\title{
PELATIHAN BACA TULIS AL-QURAN TERHADAP SANTRI MADRASAH DINIYAH TAKMILIYAH AWALIYAH (MDTA) AMANAH DI JORONG SIMPANG AMPEK NAGARI LINGKUANG AUA
}

\author{
Syofrianisda \\ Sekolah Tinggi Agama Islam (STAI) Yaptip Pasaman Barat \\ E-mail: sofialwihdah86@gmail.com
}

\begin{abstract}
The Writing of the Al-Qur'an Reading Service is based on the deepest desires of the servants that devotees want to apply science in terms of teaching reading the Qur'an that is good for the community, especially santri MDTA Amanah, Simpang Empat, West Pasaman, West Sumatra. The target to be achieved in this service is to increase the knowledge of the Amanah MDTA santi on how to read the good and correct Qur'an. The program offered at this service is a practical method in reading and writing the Qur'an so that with this method all santri can quickly read and understand the verses of the Koran they read. in this case they are grouped from the medium, low and high categories. The results achieved from this service were an average of $88,2 \%$ of students who attended the program were declared complete.
\end{abstract}

Keywords-Training, Read, Write Al-Quran

\section{Abstrak}

Pengabdian Baca Tulis al-Qur'an ini didasarkan pada keinginan yang terdalam dari pengabdi bahwa pengabdi ingin mengaplikasikan keilmuan dalam hal mengajarkan membaca alQur'an yang baik bagi masyarakat terutama santri MDTA Amanah kejorongan Simpang Empat, Kabupaten Pasaman Barat Sumatera Barat. target yang ingin dicapai dalam pengabdian ini adalah, ingin meningkatkan pengetahuan santi MDTA Amanah tentang bagaimana cara membaca alQur'an yang baik dan benar. Program yang ditawarkan pada pengabdian ini adalah metode praktis dalam membaca dan menulis al-Qur'an sehingga dengan metode ini seluruh santri bisa cepat membaca dan memahami ayat al-Quran yang mereka baca. dalam hal ini mereka dikelompokkan dari kategori sedang, rendah dan tinggi. Hasil yang dicapai dari pengabdian ini adalah rata-rata $88,2 \%$ dari santri yang mengikuti programini dinyatakan tuntas.

Kata Kunci-Pelatihan, Baca Tulis al-Qur'an

\section{PENDAHULUAN}

Al-Qur'an adalah kitab suci terakhir yang diturunkan oleh Allah SWT kepada Nabi Muhammad secara mutawatir (M. Ajaj al-Khatib, 1975. 301-302). sebagai pedoman bagi makhlukNya. Oleh karena itu ia memiliki keistimewaan yang tidak dapat diukur dengan perhitungan manusia. Di antara keistimewaannya adalah keterpeliharaan al-Qur'an dari perubahan akibat tangan-tangan kotor manusia. Allah SWT telah menjamin keterpeliharaan al-Qur'an sepanjang zaman.

Al-Qur'an sebagai suatu mukjizat tidak hanya menjadi bahan bacaan meskipun membacanya akan mendapat pahala, melainkan juga untuk difahami, dihayati, dipedomani, diamalkan dan diselidiki rahasia kebanarannya. Hal ini dimaksudkan untuk memperluas cakrawala ilmu pengetahuan tentang bukti-bukti kebesaran dan keagungan Allah, di samping itu juga untuk memenuhi kebutuhan hidup manusia, agar dapat mencapai kebahagiaan di dunia dan kesejahteraan hidup di akhirat. (M. Chadziq Charisma, 1991, 14) 


\section{Tujuan Kegiatan}

Tujuan yang ingin dicapai dalam kegiatan ini adalah memberikan pengetahuan dan keterampilan dasar mengenai Baca Tulis al-Qur'an (BTQ) dalam rangka meningkatkan kualitas iman kepada Allah SWT dan menumbuhkan perilaku baik didalam diri.

\section{Manfaat Kegiatan}

Kegiatan ini diharapkan bermanfaat bagi para peserta pelatihan Baca Tulis al-Qur'an (BTQ). Serta diharapkan minat peserta untuk lebih giat belajar setelah dilakukan pelatihan ini.

\section{Bentuk Kegiatan}

Adapun bentuk kegiatan yang dilaksanakan dalam pengabdian ini adalah sebagai berikut:

1. Pelatihan Baca Tulis al-Qur'an (BTQ).

2. Praktek membimbing tata cara shalat dan berwudhu.

3. Proses belajar mengajar melalui media tulis dan keterampilan.

\section{Tempat Kegiatan}

Kegiatan pengabdian ini dilaksanakan di Madrasah Diniyah Takmiliyah Awaliyah (MDTA) Amanah Lintang Selatan Simpang Empat Pasaman Barat.

\section{Waktu Kegiatan}

Kegiatan Pengabdian Terhadap Masyarakat melalui Pelatihan Baca Tulis al-Qur'an (BTQ) ini dilaksanakan dari tanggal 19 Mei 2014 sampai 19 Juni 2014 hari Senin-Sabtu jam 15:30-17:30 Wib (Kecuali Hari Jum'at).

\section{Agenda Kegiatan}

\begin{tabular}{cc}
\multicolumn{2}{c}{ Tabel 1. Agenda Kegiatan } \\
\hline HARI & KEGIATAN \\
\hline Senin & BTQ \\
\cline { 2 - 2 } & Fiqih \\
\hline Selasa & BTQ \\
\cline { 2 - 2 } & Hafalan Do'a \\
\hline Rabu & BTQ \\
\cline { 2 - 2 } & Hafalan Juz 'Amma \\
\hline Kamis & BTQ \\
\cline { 2 - 2 } & Praktek Shalat Fardhu \\
\hline Sabtu & BTQ \\
\cline { 2 - 2 } & Praktek Shalat Jenazah \\
\hline
\end{tabular}

\section{TINJAUAN PUSTAKA}

\section{Pengertian al-Qur'an}

Al-Qur'an merupakan kalam Allah SWT yang diturunkan kepada Nabi Muhammad SAW melalui perantaraan malaikat Jibril. Selain sebagai hujjah bagi kerasulan Muhammad Al-Qur'an juga menjadi pelajaran bagi manusia, pedoman hidup umat Islam dan petunjuk bagi orang yang bertaqwa. Karena Al-Qur'an mempunyai satu sendi utama yang esensial yang berfungsi memberi petunjuk yang sebaik-baiknya. (M. Quraish Shihab, 1994, 33) Keberadaan Al-Qur'an yang menjadi petunjuk ke jalan yang baik ini tercantum dalam firman Allah surat al-Isra' ayat 9:

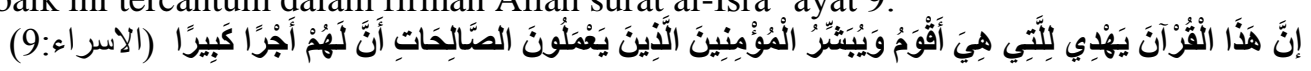
Artinya: "Sesungguhnya Al-Qur'an ini memberikan petunjuk kepada (jalan) yang lebih lurus dan memberi kabar gembira kepada orang-orang Mu'min yang mengerjakan amal saleh bahwa bagi mereka ada pahala besar". (Q.S. al-Isra':9) 
Al-Qur'an mempunyai tiga tujuan pokok, yaitu; sebagai petunjuk dalam permasalan akidah dan kepercayaan yang harus dianut oleh manusia, sebagai petunjuk mengenai akhlak, dan sebagai petunjuk mengenal syariat dan hukum. Secara singkatnya Al-Qur'an merupakan petunjuk bagi manusia ke jalan mana yang harus ditempuh untuk mendapatkan kebahagiaan hidup di dunia dan di ahkhirat. (M. Quraish Shihab, 1994, 33)

\section{Keutamaan membaca Al-Qur'an dan cara membacanya}

Dalam sebuah hadits, Rasulullah juga menerangkan bagaimana besarnya rahmat Allah terhadap orang-orang membaca Al-Qur'an di rumah-rumah peribadatan (masjid, surau dan musalla dll). Hal ini dikutkan oleh sebuah hadits yang mashur lagi shahih yang berbunyi sebagai berikut: "kepada kaum yang suka berjamaah di rumah-rumah peribadatan. Membaca Al-Qur'an secara bergiliran dan ajar-mengajarkan terhadap sesamanya. Akan turunlah kepadanya ketenangan dan ketentraman. Akan terlimpah kepadanya rahmat dan mereka akan dijaga oleh malaikat. Juga Allah akan selalu mengingat mereka" diriwayatkan oleh muslim dari abu Hurairah). (Depag RI, 1984:122).

Dengan hadits di atas nyatalah, bahwa membaca Al-Qur'an, baik mengetahui artinya ataupun tidak, adalah termasuk ibadah, amal saleh dan membari rahmad serta manfaat bagi yang melakukannya: memberi cahaya kedalam hati yang membacanya sehingga terang benderang, juga memberi cahaya kepada keluarga rumah tangga tempat Al-Qur'an itu dibaca.

Didalam senuah hadits yang diriwayatkan oleh Baihaqi dari Anas r.a. Rasulullah bersabda: "Hendaklah kamu beri Nur (cahaya) rumah tanggamu dengan sembahyang dn dengan membaca AlQur'an" (Depag RI. 1984:122).

\section{Metode Membaca al-Qur'an}

Pelaksanaan pelatihan Baca Tulis al-Qur'an (BTQ) dilakukan dengan menggunakan metode sorongan yaitu siswa membaca didepan pelatih yang menjadi pengajar dan menyimaknya. Adapun yang menjadi problem dalam pengajaran Baca Tulis al-Qur'an (BTQ) adalah semua komponen pengajaran itu sendiri meliputi: materi yang kurang lengkap, kompetensi pengajar kurang, perbedaan kecerdasan peserta, kurangnya media pengajaran. Adapun upaya yang ditempuh meliputi: berusaha melengkapi sarana prasarana menggunakan metode yang bervariasi.

Kegiatan pelatihan Baca Tulis al-Qur'an (BTQ) adalah sebuah kegiatan membaca al-Qur'an dengan tartil, artinya jelas dan teratur. Sedangkan menurut istilah ahli qiro'at ialah membaca alQur'an dengan pelan-pelan dan tenang, beserta dengan memikirkan arti-arti al-Qur'an yang sedang dibaca, semua hukum tajwid dan waqaf terjaga dengan baik dan benar/terpelihara dengan sempurna.

Dalam penggunaan metode mengajar Baca Tulis al-Qur'an (BTQ), Mahmud Yunus mengemukakan 4 metode yaitu:

1. Metode abjad, yaitu mengajarkan huruf-huruf al-Qur'an dari nama-nama huruf, kata perkata, kemudian kalimat.

2. Metode suara, yaitu ada kesamaan dengan metode abjad tetapi huruf diajarkan menurut bunyi.

3. Metode kata-kata yaitu memperhatikan kata-kata yang dibacakan guru kemudian menirukannya.

4. Metode kalimat, yaitu dimulai dari kalimat kemudian kata, kemudian huruf

\section{PELAKSANAAN KEgIATAN}

\section{Waktu Kegiatan}

Sebelum kegiatan Pengabdian Masyarakat Dosen (PMD) dilingkungan Sekolah Tinggi Agama Islam (STAI) Yaptip Pasaman Barat ini dilaksanakan, perlu diadakan persiapan sebagai berikut:

1. Mengadakan Konsultasi dengan Bapak Kepala Madrasah Diniyah Takmiliyah Awaliyah (MDTA) Amanah, meminta izin pelaksanaan Pengabdian Masyarakat Dosen (PMD) melalui pelatihan Baca Tulis al-Qur'an (BTQ), serta menetapkan hari, tanggal dan peralatan yang diperlukan. 
2. Mengadakan rapat bersama staf pengajar/guru Madrasah Diniyah Takmiliyah Awaliyah (MDTA) Amanah mengenai teknis pelatihan Baca Tulis al-Qur'an (BTQ).

3. Menyiapkan materi pembelajaran serta pelatihan Baca Tulis al-Qur'an (BTQ) beserta instrumen pembimbingan yang diperlukan agar pelaksanaan dapat mudah difahami, menarik dan lancar.

\section{Peserta}

Kegiatan pelatihan Pengabdian Masyarakat Dosen (PMD) melalui pelatihan Baca Tulis alQur'an (BTQ) ini diikuti oleh santri Madrasah Diniyah Takmiliyah Awaliyah (MDTA) Amanah sebanyak 30 orang.

\section{Proses Kegiatan}

Kegiatan ini berlangsung selama \pm 2 jam, dari pukul 15:00 - 17:00. Diawali dengan berdo'a sebelum belajar dan "yel-yel" penyemangat aktifitas belajar mengajar. Setelah itu anak-anak mulai belajar mengaji sesuai dengan tingkat kemampuan. Untuk yang belum bisa membaca al-Qur'an akan dibimbing dengan membaca iqra'.dan untuk yang sudah lancar akan diperdalam dengan mempelajari tajwid dan terjemahan al-Qur'an. Anak-anak yang sudah belajar membaca akan dibimbing untuk menulis huruf-huruf hijaiyah sampai lancar. Sedangkan untuk anak-anak yang sudah pandai membaca al-Qur'an dibimbing untuk menghafal surat pendek dan doa-doa harian. Adapun diselasela istirahat anak-anak diselingi hiburan dengan bernyanyi bersama.

Selain belajar mengaji kegiatan ini juga terdiri dari, pembelajaran ilmu fiqih, praktik shalat dan wudhu, keterampilan (menggambar dan mewarnai), kerajinan tangan, ilmu pengetahuan umum, hafalan surat pendek dan doa-doa harian.

\section{HASIL DAN PEMBAHASAN}

\section{Hasil Pengabdian}

Data dan hasil pengabdian yang akan di paparkan berikut ini terdiri atas rekaman tentang beberapa hal yang menyangkut pelaksanaan selama proses pengabdian.

Paparan data sebelum pengabdian

Pengabdian ini dilakukan pada santri kelas III di Madrasah Diniyah Awaliyah (MDA) Amanah, santri laki-laki yang terdiri dari 11 orang dan santri perempuan 22 orang, berdasarkan kemampuan akademiknya santri dalam kelas ini di klasifikasikan menjadi 5 kelompok yang berkemampuan rendah, sedang dan tinggi. Selain itu heterogen dalam kemampuan setiap santri di kelas ini dapat di lihat dari nilai ulangan pertama pada semester ganjil pada tahun 2013/2014 yang di tunjukkan pada table di bawah ini.

Tabel 2 Nilai Harian Ulangan Semester Ganjil tahun pelajaran 2013/2014.

\begin{tabular}{clc}
\hline No & \multicolumn{1}{c}{ Nama Santri } & Nilai Ulangan \\
\hline 1 & Agnes Victoria & 90 \\
\hline 2 & Aida Resti & 67 \\
\hline 3 & Aulia Fitri & 70 \\
\hline 4 & Akmal & 80 \\
\hline 5 & Ayu Permata Sari & 90 \\
\hline 6 & Desi Amelia & 60 \\
\hline 7 & Elfi Rahmi & 70 \\
\hline 8 & Fiza Soraya & 70 \\
\hline 9 & Intan Widia & 90 \\
\hline 10 & Dheo Azriel & 90 \\
\hline 11 & Khiranti Nurhalimah & 68 \\
\hline 12 & Laila Safitri & 70 \\
\hline 13 & Milatul Ikhsanah & 70 \\
\hline 14 & Olsa Andriani & 60 \\
\hline 15 & Pela Penti Zalena & 60 \\
\hline
\end{tabular}


DINAMISIA - Jurnal Pengabdian Kepada Masyarakat $\quad$ Vol. 2, No. 2 Desember 2018, Hal. 301-309

\begin{tabular}{lll}
\hline 16 & Putri Khairiah & 70 \\
\hline 17 & Riska Sulastri & 68 \\
\hline 18 & Rosyidatun Nisa' & 68 \\
\hline 19 & Sarifah Rahmaini & 90 \\
\hline 20 & Aulia Az-Zuhro & 70 \\
\hline 21 & Yusma Inar & 70 \\
\hline 22 & Gian Fernando & 70 \\
\hline 23 & Irfan Saputra & 68 \\
\hline 24 & Muhammad Aidil & 80 \\
\hline 25 & Farhan Hidayat & 80 \\
\hline 26 & Muhammad Ikbal & 70 \\
\hline 27 & Shahendari & 70 \\
\hline 28 & Fikri Haikal & 80 \\
\hline 29 & Zaki Aulia Fafhurrahman & 70 \\
\hline 30 & Suci Hartati & 70 \\
\hline 31 & Difan Safdana & 68 \\
\hline 32 & Azifah Husna & 68 \\
\hline 33 & Azka Nazifah Ulyah & 70 \\
\hline & & \\
\hline
\end{tabular}

Tabel 3 nilai ulangan harian sebelum melakukan pengabdian

\begin{tabular}{cccc}
\hline Nilai & Frekuensi & \% & Keterangan \\
\hline $80-95$ & 9 & 27,2 & T \\
$70-79$ & 14 & 42,2 & T \\
$60-69$ & 10 & 30,3 & TT \\
\hline Jumlah & 33 & 68,4 & TT \\
\hline
\end{tabular}

Dari hasil nilai ulangan harian pada semester ganjil maka perlu melakukan bimbingan khusus agar prestasi dan partisipasi santri dalam melakukan pembelajaran dapat meningkat sesuai dengan tujuan yang dicapai.

Pada metode pembelajaran kooperatif bercirikan kelompok-kelompok, santri sebagai sarana untuk mendiskusikan dan menyelesaikan masalah, permasalahan-permasalah yang berkaitan dengan materi yang sedang di bahas.

Pembentukan kelompok berdasarkan nilai ulangan harian sebelumnya sehingga pada pelaksanaan pengabdian initi dak menggunakan tes kemampuan awal. Oleh karena itu pembentukan kelompok di lihat dari hasil nilai ulangan Madrasah Diniyah Awaliyah (MDA) Amanah Kelas III di kelompokkan menjadi dua kelompok dengan ketentuan Santri dengan nilai 75 minimal sudah memenuhi SKM (sudah tuntas).

Dari tiga kelompok tersebut kemudian di bentuk Tujuh kelompok secara heterogen, artinya setiap kelompok santri yang terdiri dari santri yang berkemampuan rendah, sedang, tinggi.Dan kelompok tersebut terbentuk dilihat pada tabel di bawah ini.

Tabel 4 Daftar Anggota Kelompok

\begin{tabular}{clll}
\hline Kelompok & Nama Santri & & Kemampuan \\
\hline S & Agnes Victoria & 90 & Tinggi \\
$\mathrm{A}$ & Aida Resti & 67 & Rendah \\
$\mathrm{T}$ & Aulia Fitri & 70 & Sedang \\
$\mathrm{U}$ & Akmal & 80 & Tinggi \\
& Ayu Permata Sari & 90 & Tinggi \\
$\mathrm{D}$ & Desi Amelia & 60 & Rendah \\
$\mathrm{U}$ & Elfi Rahmi & 70 & Sedang \\
$\mathrm{A}$ & Fiza Soraya & 70 & Sedang \\
& Intan Widia & 90 & Tinggi \\
& Dheo Azriel & 90 & Tinggi \\
\hline
\end{tabular}


DINAMISIA - Jurnal Pengabdian Kepada Masyarakat $\quad$ Vol. 2, No. 2 Desember 2018, Hal. 301-309

\begin{tabular}{|c|c|c|c|}
\hline Kelompok & Nama Santri & & Kemampuan \\
\hline $\mathrm{T}$ & Khiranti Nurhalimah & 68 & Rendah \\
\hline I & Laila Safitri & 70 & Sedang \\
\hline G & Milatul Ikhsanah & 70 & Sedang \\
\hline \multirow[t]{2}{*}{ A } & Olsa Andriani & 60 & Rendah \\
\hline & Pela Penti Zalena & 60 & Rendah \\
\hline $\mathrm{E}$ & Putri Khairiah & 70 & Sedang \\
\hline M & Riska Sulastri & 68 & Rendah \\
\hline $\mathrm{P}$ & Rosyidatun Nisa' & 68 & Rendah \\
\hline A & Sarifah Rahmaini & 90 & Tinggi \\
\hline $\mathrm{T}$ & Aulia Az-Zuhro & & Sedang \\
\hline $\mathrm{L}$ & Yusma Inar & 70 & Sedang \\
\hline I & Gian Fernando & 70 & Sedang \\
\hline M & Irfan Saputra & 68 & Rendah \\
\hline \multirow{2}{*}{ A } & Muhammad Aidil & 80 & Tinggi \\
\hline & Farhan Hidayat & & Tinggi \\
\hline $\mathrm{E}$ & Muhammad Ikbal & 70 & Sedang \\
\hline $\mathrm{N}$ & Shahendari & 70 & Sedang \\
\hline A & Fikri Haikal & 80 & Tinggi \\
\hline M & Zaki Aulia Fafhurrahman & 70 & Sedang \\
\hline $\mathrm{T}$ & Suci Hartati & 70 & Sedang \\
\hline $\mathrm{U}$ & Difan Safdana & 68 & Rendah \\
\hline $\mathrm{J}$ & Azifah Husna & 68 & Rendah \\
\hline $\mathrm{U}$ & Azka Nazifah Ulyah & 70 & Sedang \\
\hline $\mathrm{H}$ & & & \\
\hline
\end{tabular}

Setelah membagi santri dalam kelompok-kelompok heterogen seperti pada tabel yang telah di paparkan 1.2. kemudian mengumumkan hasil pembentukan kelompok tersebut kepada santri.

Pengabdian ini di mulai dari pertemuan kedua dari pembahasan fiqih materi Thaharah. Pertemuan pertama di lakukan pada hari Senin 19 Mei 2014 mulai jam15:30 sampai 17:30 Wib. Materi yang di bahas adalah Makharijul Huruf.

Tabel 5. Prestasi santri dalam mengikuti pengabdian

\begin{tabular}{|c|c|c|c|c|c|c|}
\hline \multirow[b]{2}{*}{ No } & \multirow[b]{2}{*}{ Nama Santri } & \multirow[t]{2}{*}{$\begin{array}{l}\mathbf{L} / \\
\mathbf{P}\end{array}$} & \multicolumn{3}{|c|}{$\begin{array}{c}\text { Nilai Ulangan } \\
\text { Harian }\end{array}$} & \multirow{2}{*}{$\begin{array}{c}\text { Tuntas } \\
\text { Tidak } \\
\text { Tuntas }\end{array}$} \\
\hline & & & I & 2 & $\begin{array}{c}\text { Rata- } \\
\text { rata }\end{array}$ & \\
\hline 1 & Agnes Victoria & $\mathrm{P}$ & 90 & 70 & 80,0 & $\mathrm{~T}$ \\
\hline 2 & Aida Resti & $\mathrm{P}$ & 60 & 68 & 64,0 & TT \\
\hline 3 & Aulia Fitri & $\mathrm{P}$ & 65 & 75 & 70,00 & $\mathrm{~T}$ \\
\hline 4 & Akmal & $\mathrm{L}$ & 90 & 85 & 87,5 & $\mathrm{~T}$ \\
\hline 5 & Ayu Permata Sari & $\mathrm{P}$ & 80 & 90 & 87,5 & $\mathrm{~T}$ \\
\hline 6 & Desi Amelia & $\mathrm{P}$ & 58 & 70 & 64,00 & TT \\
\hline 7 & Elfi Rahmi & $\mathrm{P}$ & 70 & 65 & 67,5 & TT \\
\hline 8 & Fiza Soraya & $\mathrm{P}$ & 50 & 80 & 65,0 & TT \\
\hline 9 & Intan Widia & $\mathrm{P}$ & 80 & 90 & 87,5 & $\mathrm{~T}$ \\
\hline 10 & Dheo Azriel & $\mathrm{L}$ & 75 & 85 & 80,0 & $\mathrm{~T}$ \\
\hline 11 & Khiranti Nurhalimah & $\mathrm{P}$ & 80 & 70 & 67,5 & TT \\
\hline 12 & Laila Safitri & $\mathrm{P}$ & 80 & 70 & 67,5 & TT \\
\hline 13 & Milatul Ikhsanah & $\mathrm{P}$ & 62 & 70 & 66,0 & TT \\
\hline 14 & Olsa Andriani & $\mathrm{P}$ & 70 & 65 & 67,5 & TT \\
\hline
\end{tabular}


DINAMISIA - Jurnal Pengabdian Kepada Masyarakat $\quad$ Vol. 2, No. 2 Desember 2018, Hal. 301-309

\begin{tabular}{|c|c|c|c|c|c|c|}
\hline \multirow[b]{2}{*}{ No } & \multirow[b]{2}{*}{ Nama Santri } & \multirow[t]{2}{*}{$\begin{array}{l}\mathbf{L} / \\
\mathbf{P}\end{array}$} & \multicolumn{3}{|c|}{$\begin{array}{c}\text { Nilai Ulangan } \\
\text { Harian }\end{array}$} & \multirow{2}{*}{$\begin{array}{c}\text { Tuntas } \\
\text { Tidak } \\
\text { Tuntas }\end{array}$} \\
\hline & & & $\mathbf{I}$ & 2 & $\begin{array}{c}\text { Rata- } \\
\text { rata }\end{array}$ & \\
\hline 15 & Pela Penti Zalena & $\mathrm{P}$ & 68 & 90 & 79,0 & $\mathrm{~T}$ \\
\hline 16 & Putri Khairiah & $\mathrm{P}$ & 70 & 75 & 72,5 & $\mathrm{~T}$ \\
\hline 17 & Riska Sulastri & $\mathrm{P}$ & 68 & 85 & 80,0 & $\mathrm{~T}$ \\
\hline 18 & Rosyidatun Nisa' & $\mathrm{P}$ & 65 & 65 & 65,0 & TT \\
\hline 19 & Sarifah Rahmaini & $\mathrm{P}$ & 80 & 90 & 85,0 & $\mathrm{~T}$ \\
\hline 20 & Aulia Az-Zuhro & $\mathrm{P}$ & 70 & 70 & 70,0 & $\mathrm{~T}$ \\
\hline 21 & Yusma Inar & $\mathrm{P}$ & 68 & 85 & 80,0 & $\mathrm{~T}$ \\
\hline 22 & Gian Fernando & $\mathrm{L}$ & 65 & 65 & 65,0 & TT \\
\hline 23 & Irfan Saputra & $\mathrm{L}$ & 65 & 75 & 67,5 & TT \\
\hline 24 & Muhammad Aidil & $\mathrm{L}$ & 75 & 80 & 77,5 & $\mathrm{~T}$ \\
\hline 25 & Farhan Hidayat & $\mathrm{L}$ & 68 & 85 & 80,0 & $\mathrm{~T}$ \\
\hline 26 & Muhammad Ikbal & $\mathrm{L}$ & 65 & 65 & 65,0 & TT \\
\hline 27 & Shahendari & $\mathrm{L}$ & 65 & 68 & 66,5 & TT \\
\hline 28 & Fikri Haikal & $\mathrm{L}$ & 70 & 80 & 75,0 & $\mathrm{~T}$ \\
\hline 29 & Zaki Aulia Fafhurrahman & $\mathrm{L}$ & 80 & 80 & 80,0 & $\mathrm{~T}$ \\
\hline 30 & Suci Hartati & $\mathrm{P}$ & 60 & 75 & 67,5 & TT \\
\hline 31 & Difan Safdana & $\mathrm{L}$ & 65 & 68 & 66,5 & TT \\
\hline 32 & Azifah Husna & $\mathrm{P}$ & 62 & 70 & 66,0 & TT \\
\hline 33 & Azka Nazifah Ulyah & $\mathrm{P}$ & 58 & 70 & 64,0 & TT \\
\hline
\end{tabular}

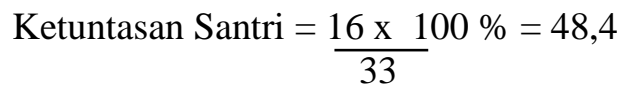

Tabel 6. Frekuensi Nilai Ulangan Semester Ganjil pada siklus I di MDA Amanah

\begin{tabular}{cccc}
\hline Nilai & Frekuensi & \% & Keterangan \\
\hline $80-95$ & 10 & 33,3 & $\mathrm{~T}$ \\
$70-79$ & 6 & 18,8 & $\mathrm{~T}$ \\
$60-69$ & 17 & 59,4 & TT \\
Jumlah & 33 & 48,4 & TT \\
\hline
\end{tabular}

Tabel diatas menunjukkan bahwa prestasi belajar santri belum memenuhi kreteria ketuntasan dengan angka sebesar $48,4 \%$

Tabel 7. Nilai Ulangan Harian2013/2014

\begin{tabular}{|c|c|c|c|c|c|c|}
\hline \multirow[t]{2}{*}{ No } & \multirow{2}{*}{ Nama Santri } & \multirow{2}{*}{$\mathbf{L} / \mathbf{P}$} & \multicolumn{3}{|c|}{ Nilai Ulangan Harian } & \multirow{2}{*}{$\begin{array}{c}\text { Tuntas } \\
\text { Tidak Tuntas }\end{array}$} \\
\hline & & & I & 2 & Rata-rata & \\
\hline 1 & Agnes Victoria & $\mathrm{P}$ & 90 & 70 & 80,0 & $\mathrm{~T}$ \\
\hline 2 & Aida Resti & $\mathrm{P}$ & 60 & 68 & 64,0 & $\mathrm{TT}$ \\
\hline 3 & Aulia Fitri & $\mathrm{P}$ & 65 & 75 & 70,00 & $\mathrm{~T}$ \\
\hline 4 & Akmal & $\mathrm{L}$ & 90 & 85 & 87,5 & $\mathrm{~T}$ \\
\hline 5 & Ayu Permata Sari & $\mathrm{P}$ & 80 & 90 & 87,5 & $\mathrm{~T}$ \\
\hline 6 & Desi Amelia & $\mathrm{P}$ & 58 & 70 & 64,00 & TT \\
\hline 7 & Elfi Rahmi & $\mathrm{P}$ & 70 & 65 & 67,5 & TT \\
\hline 8 & Fiza Soraya & $\mathrm{P}$ & 50 & 80 & 65,0 & TT \\
\hline 9 & Intan Widia & $\mathrm{P}$ & 80 & 90 & 87,5 & $\mathrm{~T}$ \\
\hline 10 & Dheo Azriel & $\mathrm{L}$ & 75 & 85 & 80,0 & $\mathrm{~T}$ \\
\hline 11 & Khiranti Nurhalimah & $\mathrm{P}$ & 80 & 70 & 67,5 & TT \\
\hline 12 & Laila Safitri & $\mathrm{P}$ & 80 & 70 & 67,5 & TT \\
\hline
\end{tabular}


DINAMISIA - Jurnal Pengabdian Kepada Masyarakat $\quad$ Vol. 2, No. 2 Desember 2018, Hal. 301-309

\begin{tabular}{|c|c|c|c|c|c|c|}
\hline \multirow[t]{2}{*}{ No } & \multirow[t]{2}{*}{ Nama Santri } & \multirow[t]{2}{*}{$\mathbf{L} / \mathbf{P}$} & \multicolumn{3}{|c|}{ Nilai Ulangan Harian } & \multirow{2}{*}{$\begin{array}{c}\text { Tuntas } \\
\text { Tidak Tuntas }\end{array}$} \\
\hline & & & I & 2 & Rata-rata & \\
\hline 13 & Milatul Ikhsanah & $\mathrm{P}$ & 62 & 70 & 66,0 & TT \\
\hline 14 & Olsa Andriani & $\mathrm{P}$ & 70 & 65 & 67,5 & TT \\
\hline 15 & Pela Penti Zalena & $\mathrm{P}$ & 68 & 90 & 79,0 & $\mathrm{~T}$ \\
\hline 16 & Putri Khairiah & $\mathrm{P}$ & 70 & 75 & 72,5 & $\mathrm{~T}$ \\
\hline 17 & Riska Sulastri & $\mathrm{P}$ & 68 & 85 & 80,0 & $\mathrm{~T}$ \\
\hline 18 & Rosyidatun Nisa' & $\mathrm{P}$ & 65 & 65 & 65,0 & TT \\
\hline 19 & Sarifah Rahmaini & $\mathrm{P}$ & 80 & 90 & 85,0 & $\mathrm{~T}$ \\
\hline 20 & Aulia Az-Zuhro & $\mathrm{P}$ & 70 & 70 & 70,0 & $\mathrm{~T}$ \\
\hline 21 & Yusma Inar & $\mathrm{P}$ & 68 & 85 & 80,0 & $\mathrm{~T}$ \\
\hline 22 & Gian Fernando & $\mathrm{L}$ & 65 & 65 & 65,0 & TT \\
\hline 23 & Irfan Saputra & $\mathrm{L}$ & 65 & 75 & 67,5 & TT \\
\hline 24 & Muhammad Aidil & $\mathrm{L}$ & 75 & 80 & 77,5 & $\mathrm{~T}$ \\
\hline 25 & Farhan Hidayat & $\mathrm{L}$ & 68 & 85 & 80,0 & $\mathrm{~T}$ \\
\hline 26 & Muhammad Ikbal & $\mathrm{L}$ & 65 & 65 & 65,0 & TT \\
\hline 27 & Shahendari & $\mathrm{L}$ & 65 & 68 & 66,5 & TT \\
\hline 28 & Fikri Haikal & $\mathrm{L}$ & 70 & 80 & 75,0 & $\mathrm{~T}$ \\
\hline 29 & Zaki Aulia Fafhurrahman & $\mathrm{L}$ & 80 & 80 & 80,0 & $\mathrm{~T}$ \\
\hline 30 & Suci Hartati & $\mathrm{P}$ & 60 & 75 & 67,5 & TT \\
\hline 31 & Difan Safdana & $\mathrm{L}$ & 65 & 68 & 66,5 & TT \\
\hline 32 & Azifah Husna & $\mathrm{P}$ & 62 & 70 & 66,0 & TT \\
\hline 33 & Azka Nazifah Ulyah & $\mathrm{P}$ & 58 & 70 & 64,0 & TT \\
\hline
\end{tabular}

Ketuntasan Santri $=28 \quad \times \overline{100 \%}=88,2 \%$

33

Tabel 8. Distribusi Frekuensi Nilai Ulangan Madrasah Diniyah Awaliyah (MDA) Amanah

\begin{tabular}{cccc}
\hline Nilai & Frekuensi & \% & Keterangan \\
\hline $80-95$ & 8 & 24,2 & $\mathrm{~T}$ \\
$70-79$ & 22 & 66,7 & $\mathrm{~T}$ \\
$60-69$ & 3 & 09,1 & $\mathrm{~T}$ \\
\hline Jumlah & 33 & 88,2 & Tuntas \\
\hline
\end{tabular}

Tabel diatas pada menunjukkan bahwa prestasi santri telah tuntas dengan angka sebesar $88,2 \%$

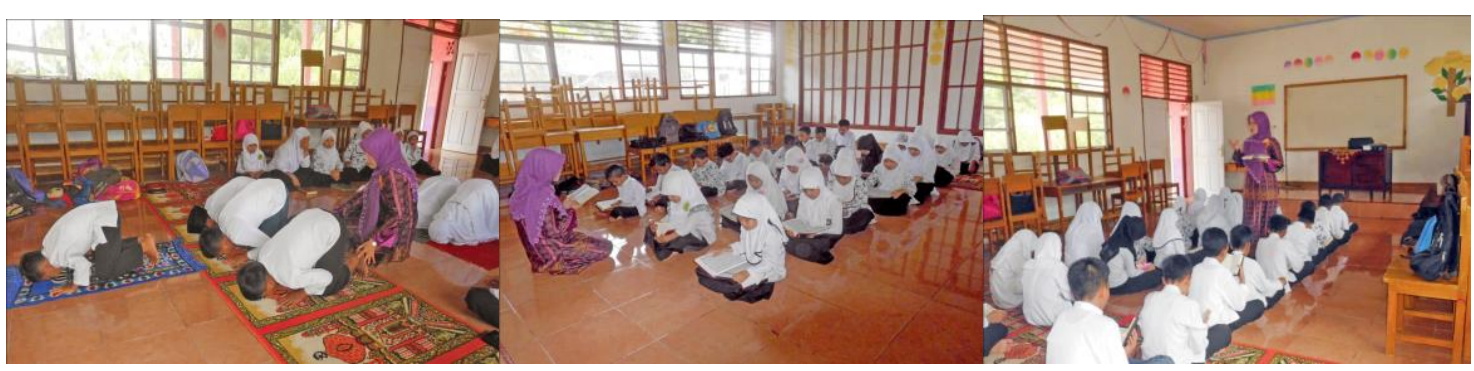

Gambar 1 Photo Kegiatan 


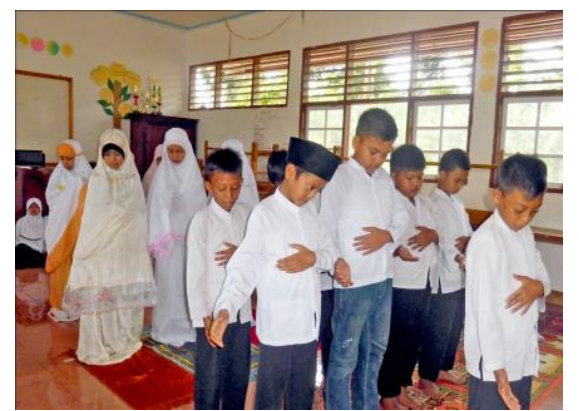

Gambar 2. Foto Bimbingan Shalat Fardhu

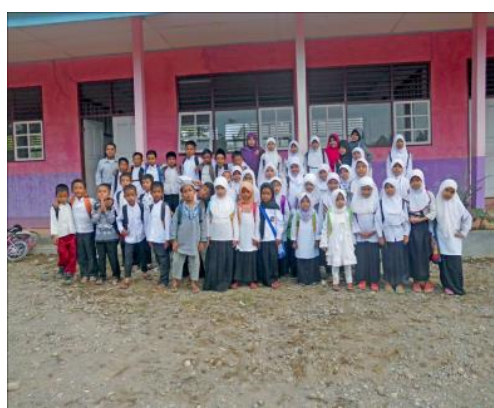

Pembahasan

Sejumlah 33 orang peserta yang terdiri atas anak-anak usia 6-12 tahun mendapat pengajaran tentang membaca dan menulis Al-Qur'an. Berdasarkan hasil pelatihan selama 1 bulan, dapat diketahui kemajuan pengetahuan peserta menyangkut materi yang telah disampaikan. Bisa dilihat peningkatan pengetahuan mereka secara signifikan. Terlihat bahwa rata-rata mereka telah memperoleh tambahan pengetahuan yang cukup memadai perihal apa yang telah dimaterikan. Oleh sebab itu diharapkan peserta pelatihan dapat memanfaatkan pengetahuan ini untuk lebih mengoptimalkan ilmu pengetahuan.

\section{KESIMPULAN}

Pendidikan al-Qur'an sejak dini memang sangat diperlukan terutama pada masa 'golden age' dimana pola pikir anak-anak yang masih jernih dan daya ingat yang kuat dapat menjadi kesempatan emas bagi orang tua untuk memberikan pelajaran yang baik. Demi pembentukan kepribadian anak yang cemerlang dan berkelanjutan. Pelatihan Baca Tulis Al-Qur'an (BTQ) dapat menjadi sarana efektif bagi penerapan ilmu-ilmu islam. Sebab Al-Qur'an adalah pedoman bagi seluruh umat islam yang kelak akan memberi petunjuk bagi generasi-generasi muda untuk menjadi pribadi yang baik seperti Rasulullah.

\section{DAFTAR PUSTAKA}

[1] Al-Khatib, M. Ajaj Ushul al-Hadis, Beirut: Dar al-Fikri, 1975

[2] Charisma, M. Chadziq, Tiga Aspek Kemukjizatan al-Qur'an, Surabaya: Bina Ilmu, 1991

[3] Shihab, Muhammad Quraish, Membumikan Al-Qur'an fungsi dan peran wahyu dalam kehidupan masyarakat), Bandung: Mizan, 1994

[4] 'Ishom, Muhammad, Al-Waadlih fi Ahkaam al-Tajwiid, Daar al-Nafa'is, T Th.

[5] Zainuddin, at-Taisir bi Syarkhi al-Jami' ash-Shoghir, 1988, Riyadh: Maktabah al-Imam asySyafi'i, (Maktabah Syamilah) 